\title{
Did the Great Recession affect young people's aspirations and reinforce social inequality?
}

\author{
Walter R. Heinz, BIGSSS, University of Bremen, Germany \\ walter.r.heinz@web.de
}

(Received March 2014 Revised April 2014)

http://dx.doi.org/10.14301/Ilcs.v5i2.288

In the first decade of the $21^{\text {st }}$ century, youth transition research in Europe (Buchmann \& Kriesi, 2011) and in North America (Crosnoe \& Johnson, 2011) made a great leap forward. This progress is largely attributable to continuing panel studies and advances in data analysis, but also to the pressing need to understand the dramatic changes in labour markets and the rising costs of education in the UK and USA, that impact families and their offspring's transition to adulthood. In the fall of 2013, 7.8\% of 15-24 year olds were unemployed in Germany, 15\% in the USA (16-24), and 20\% in Great Britain. The situation was much worse in Portugal with $36.5 \%$, and in Spain with $57 \%$ of young people unemployed.

The papers in this Special Section study the effects of the Great Recession on youth transitions in three countries, by analysing longitudinal data and asking the following questions:

What are the effects of changing labour markets on employment opportunities of young people?

Did youth, who were confronted with economic hardship in their families and more demanding educational pathways as well as employment risks, lower their aspirations and adjust their educational and job expectations?

Does social class background become more consequential for growing up in poverty and for poverty risks in young adulthood?

To what extent are contemporary adolescents' and young adults' ambitions affected by their parents' employment history and their changing economic conditions; do they rewrite their life scripts and alter their plans for the future?

Do changing economic circumstances intervene in young people's identity development when they lack resources for investing in their futures?

While the focus here is on individuals and families, to fully understand the effects of the Great
Recession on youth transitions one must consider social policy arrangements at the macro-societal level - the manner in which societies respond to the economic hardships of their citizens. Systematic comparative analysis, focusing on institutions and social pathways, is sorely needed.

Due to economic globalization and the financial crisis, a climate of uncertainty in regard to future life paths has been spreading (Blossfeld, Klijzing, Mills, and Kurz, 2005; Heinz, 2009) in the last decade. In their review of youth studies, Buchmann and Kriesi $(2011,491)$ drew a sober conclusion: "Anxiety about the future, low life satisfaction, and uncertain employment prospects have been shown to lead to postponement or forgoing of child bearing plans and to affect educational decisions."

Young people who have to navigate their multiple transitions to adulthood are confronted with rising skill demands in highly competitive education and employment markets. This is a competition in which youth from disadvantaged families have few chances to succeed, or even participate, without parents who stress high educational aspirations and promote selfconfidence, as the papers in this issue show. However, in addition to good parenting, families at risk need material and social resources for preparing their children to become self-reliant agents of their multiple transitions, by directing and accompanying them towards promising pathways.

It is an often repeated insight, a truism by now, that structured opportunities and constraints, as well as individual motivation and competence, determine the outcomes of transitions. Moreover, micro-social factors, actors' social and psychological characteristics and their family backgrounds, play a crucial role in transitions, as individuals encounter the institutions and the social policy regimes that structure education and labour markets and define the responsibility of families. 
It is quite a challenge to study transitions as a process in a theoretical framework that takes into account more than one dimension of the life course and the interaction of social structure, markets, institutions and individual actors across time. For example, the timing of leaving home varies by country and by gender and has become a reversible status passage with diverse destinations - studying, looking for work, employment and unemployment episodes, cohabiting, and forming a family. And, youth unemployment rates vary by country and within countries as well as by the vocational and academic pathways of graduates. For explaining such differences, educational pathways, family resources, labour markets, and public policy on the one hand, and young people's abilities, aspirations and orientations on the other hand, must be related to each other, as direct and indirect determinants of transition outcomes.

The complexity of analysing transitions across the life course was aptly characterized recently by Crosnoe and Johnson $(2011,440)$ when they called: "lives as a tapestry of three threads developmental trajectories, social pathways, and social convoys - situated in settings of daily life, larger structures of society, and the broader sweep of history."

Youth research in a life course framework examines how life conceptions and future plans are transmitted by parents and how they affect the transition to adulthood. The contextual approach adds to the analysis the impacts of the structure of social inequality, family resources, and the accessibility of social pathways on the outcome of transitions.

In all three countries, educational expectations are rising: staying-on in the UK; entering the postsecondary tracks after high school in the USA, including enrollment in community colleges and four year colleges; and in Germany, university entrance, "dual studies," or vocational education and training (VET). But, aspirations tend to be higher than actual attainment; many young adults are dropping out because of financial pressures and return to college in evening classes. Since school and training pathways and transfer options vary by the respective educational cultures and labour market regulations that interact with institutional arrangements, young people are confronted with different transition regimes.
Given diverse institutional arrangements and changing opportunity structures, it is becoming essential that parents provide material and emotional support beyond adolescence and attempt to assist their children in negotiating the process of growing up, together with the influence of siblings, friends, and peer groups. There are no solo transitions; instead they are embedded in social convoys, overlapping relationships, and sometimes competing attachments.

Parental education and employment histories are reflected in their world views and socialization practices and shape their responses to changing economic circumstances and sudden income loss due to unemployment. As shown in many years of socialization research and more recently by Lareau (2004) for example, it is mainly middle-class parents who provide activity spaces and opportunities that promote their offspring's cognitive and social competencies which are useful for navigating pathways and dealing with institutions. It is likely that this parenting style transmits a social-class based portfolio of ambitions and self-efficacy that creates long-term advantages for the life course.

The four papers cover a lot of ground concerning the transition of young people in a period of economic uncertainty and rising unemployment. Key overarching questions connect the papers: how do the consequences of unemployment and poverty extend, via family life, to the next generation? To what extent do ambitions and achievement orientations mediate the impact of economic hardship and disadvantage on the future planning of young people?

The inter-generational transmission of individual orientations and structural locations, with a focus on poverty risks, is a central theme. These papers invite the reader to compare the impacts of the Great Recession on the socialization and life chances of youth in the UK, USA, and Germany, illuminated by sophisticated modelling of longitudinal data on transitions and outcomes.

First, let us look at the restructuring of opportunities in the school-employment nexus: in all three societies, changes in school-to-work pathways and post-secondary education occurred before the onset of the Great Recession; the 'vanishing youth labour market' and the expansion of higher education have greatly affected the timing and duration of transitions. 
The nationally representative "Monitoring the Future Study" provides data that document how teenage employment has been declining in the USA since 2006 and during the period of the Great Recession. Staff, Johnson, Patrick and Schulenberg (this issue) show with six cohorts of 8th, 10th, and $12^{\text {th }}$ graders that the reduction of part-time jobs (which used to be largely teenage-jobs) in the USA has reduced students' chances to gain work experience that contributes to their vocational development and to build connections with potential employers (for consideration of the meaning of work for growing up in America, see Mortimer, 2003). Self-reported employment experiences of youth in the age group between 13 and 18 documented that they tended to obtain more or less informal jobs in restaurants, farming, offices, or retail sales, instead of working in manufacturing and construction industries.

These changes in school-to-work pathways result from the rising learning demands in high school and rising ambitions to go to college on the one side, and changing employers' preferences for adult workers, who want to escape from unemployment, on the other.

Staff et al ask whether minority adolescents are more affected than whites and whether social class and gender matter? The decline of jobs especially hurts those adolescents who are weary of school and drop-outs, and thus young people at risk, because work experiences tend to stabilize their transition to adulthood, providing an alternative to hanging around in shopping malls and deviant behaviour.

This study suggests that young people did not withdraw from jobs voluntarily; instead, contemporary youth cannot find employment anymore that can easily be combined with school. The teens at the end of high school are competing with adults who are looking for work. US youth are not really leaving the job market, they are rather squeezed out by employers' changing preferences for temporary adult workers. Staff et al conclude that there is no decline of interest in work among high school students in the past 30 years; moreover, those who do find work are employed in informal instead of semi-skilled jobs. The desire to find some employment persists despite the trend toward higher education.

Thus, for a growing number of high school students in the United States, anticipating college overrides the preparation for employment. In contrast, German high level school ("Gymnasium") graduates are increasingly diversifying their pathways: most pursue the traditional university pathway, while others embark on vocational education and training (VET) or enter the new pathway of "dual studies" that combines the BA with an occupational certificate, a joint venture of employers and colleges. Staff et al (this issue, $p$. 176) conclude: "The salience of educational degrees may have also grown, as a strategy for bolstering one's continued employability across the life course in more uncertain times."

Did the Great Recession reinforce changes in the transition process that resulted from ongoing demographic transformation, labour market shifts to service jobs, and the trend toward postsecondary education? Teenage employment declined further during this period and fewer students had jobs after the official end of the Great Recession.

Surprisingly, parents' education did not matter in regard to the teenagers' employment rate, a finding that contradicts the assumption that adolescents look for work because of economic incentives. They rather regard this activity as a component of their transition. The lack of jobs, however, hurts the young people from disadvantaged families and neighbourhoods who need an occupational perspective, social skills and contacts from teenage work.

This is becoming a serious issue for life course policy reforms, which must focus on mentoring students and connecting schools with the local job market.

Turning to the German experience, the living circumstances for a growing number of young people have declined in recent years despite that country's successful coping with the consequences of the Great Recession. Economic growth, driven more by export than consumption, and a low unemployment rate could not narrow the gap between the well-to-do and the lower class that has been deepening in Germany since the beginning of this century. There is employment growth, however, with an expanding low-wage sector and temporary employment. As Groh-Samberg and Voges (this issue) document, based on the German Socio-Economic Panel Study (GSOEP), children and youth growing up in low income families and those receiving public assistance are highly vulnerable. 
Focusing on the social class structure of Germany, they analysed the causes and consequences of youth poverty in a life course framework. SOEP household panel data are used to answer two questions: first, the extent to which parents support their children when leaving home; second, life course consequences of growing up in a poor family. There are different mechanisms of parental support, depending on the transition requirements and the families' capacities. Which ones are used?

This study is remarkable, as it offers a wide window of observation - the data cover the period from 1995 to 2011, the official end of the Great Recession, and it maps transitions in three main life course spheres, family formation, educational attainment, and labour market allocation.

Instead of regarding young people as selfsupporting actors, the authors present a novel approach to estimating youth poverty. By taking into account the income of the family of origin, the rate of young people's poverty is reduced substantially. Thus, the determination of parents' support (transferred income) is based on the concept of independent, but financially linked households ("virtual family reunification").

Age groups are differentially affected: adolescents between ages 15 and 19, most of them still living at home, have the highest risk of poverty. Poverty risk is also high for young adults (age 26-30) who are struggling for an independent living arrangement in the labour and housing markets. An explanation is indicated, as the rates of leaving home differ by social class: youth from poor and rich families leave earlier, though for different reasons, than from middle class households.

There is a long-term trend of increasing social disparity in Germany, a spread of disadvantage in the risk zone of the working poor. The poverty rate increased during the Great Recession as recent figures (WZB "Social Report" 2013) document from $2007(15.2 \%)$ to $16.1 \%$ in 2011 . The age groups between 18 and 24 and between 55 and 64 years are confronted with a higher risk of poverty, with $19 \%$ and $20.3 \%$, respectively, than the middle age groups. There are vast regional differences; migrants and young people living in East German regions are more affected because of a depressed labour market.

Is youth poverty a prelude to a disadvantaged adulthood? Results suggest that the earlier stages of the life course have profound consequences later in life. As Groh-Samberg and Voges show, social background, measured by parental education, became more important as a source of poverty in young adulthood. This is an interesting result: The transition to an independent way of life seems to initially weaken the impact of social origin, but social class effects are returning when independence is reached. My guess is that the institutionalized transition pathways in Germany provide a temporary stability but then deliver their graduates into a stratified occupational market.

Since we do not know enough about the social mechanism of the inter-generational transmission of poverty, we must speculate whether there is a new culture of poverty (Valentine, 1968) or of worklessness (Shildrick, MacDonld, Furlong, Roden, and Crow2012) or even a new social class of the precariat (Standing, 2011) emerging, driven by the lack of secure employment and a decline of achievement orientations, when the number of neighbourhoods with families who raise their children in a context of economic hardship from generation to generation is increasing.

This issue is taken up at least in part by Schoon's paper (this issue). There were over one million workless households with dependent children in the UK in 2011. Does growing up in a jobless family extend its influence into volatile educational attainment and precarious employment, which result in becoming a client of the social security system? Previous research shows that sons of fathers who were jobless in their childhood were over twice as likely to have workless spells themselves. Therefore, it is important to find out how unemployed parents are communicating this situation to their children. Does their experience influence the way young people see their own futures, do they continue with high achievement orientations or do their financial restrictions block initiative and aspirations?

Schoon's analysis uses data from the Longitudinal Study of Young People in England (LSYPE), a large sample of more than 10,000 respondents. She illuminates the process by which young people carry the experience of parental job loss into the precarious pathway of NEET (Not in Education, Employment or Training), with special attention to gender differences. The study is set in the theoretical framework of a "developmentalcontextual perspective" with a focus on the mediating role of educational aspirations and 
expectations. Schoon asks, to what extent do ambitions remain alive in disadvantaged living circumstances and economic uncertainty and how do they moderate the effects of parental worklessness?

In view of the dramatic increase in the unemployment rate among $16-24$ year olds to $20 \%$ in England, we must consider the reasons for being (stuck) in NEET and the ways to get out of this predicament. Does NEET become a temporary pathway in the transition to adulthood for schoolleavers who live in a workless household?

Schoon also examines whether the child's agency (educational optimism and expectation to enter higher education) mediates and moderates the consequences of parental worklessness for their own employment in young adulthood. The assumption derived from status attainment literature is a strong one: optimism toward the future and educational aspirations are pro-active resources that may reduce the detrimental effects of parental social and economic hardship on the young person's transition.

However, when confounding factors are introduced, like the parent's education, living circumstances, household composition, and sociogeographic area (as measured by the Index of Multiple Deprivation), the effect of parental worklessness on NEET status diminishes. Furthermore, among young people with ethnic minority background, the accumulation of disadvantage and of risk factors can be moderated by high educational aspirations. This result may apply primarily to second-generation Asian immigrants, but ethnic background was not differentiated.

The study also analyses the duration of parental unemployment and of being NEET (between ages 16 and 20). Three family employment patterns are distinguished - parents who are continuously working; temporary jobless; and persistently jobless.

Between 2004 and 2006, i.e. before the onset of the Great Recession, $10 \%$ of the young people lived in a persistent jobless family, and $5 \%$ in a context determined by temporary worklessness; there were no gender differences. The young people were characterised by ethnic background, school performance at age 11, and achievement orientation.

As shown in models 1 and 2 (Tables 2 and 3), the association between parental worklessness and young people's achievement orientation can largely be explained by the families' socio-demographic characteristics. A closer look, however, suggests interaction effects, as young people's individual characteristics matter (model 4, Tables 2 and 3), too: young men and women from persistently and temporarily workless families do not benefit as much from high levels of prior educational achievement as do those from stable working families.

In regard to NEET, the association between family worklessness and NEET is largely due to the families' social and economic circumstances for boys and girls. Schoon's Model 4 (Tables 4 and 5) indicates that the risk of offspring NEET in a persistently workless family is reduced when the young person has a high level of achievement orientation, though the risk factors of single parenthood (for males only), rented accommodation, and area of multiple deprivation matter too.

Worklessness alone does not seem to explain why young people are trapped in NEET and its duration; instead, the level of parental education, lack of home ownership, large family size, single parenthood, and living in an area with multiple sources of deprivation are driving factors. The neighbourhood seems to have an important effect on becoming NEET, maybe because the peers share disappointing school experiences and potential employers read the area's reputation with a concentration of high risk youth as a negative signal. School attainment, the intention to stay-on, and ethnic minority status reduce the risk of being long-term NEET.

An encouraging result is that most of the adolescents in workless families want to stay on an educational pathway ( $75 \%$ boys, $91 \%$ girls); however, the proportion aiming for university drops to $42 \%$ for males and $58 \%$ for females, compared to $61 \%$ of boys and $72 \%$ of girls who live in a working family. A recent British study, based on the LSYPE (Micklewright \& Anders, 2013) confirms this result: $20 \%$ of students who were good in school at age 11 did not apply to university by age 20 . A strong social class effect was observed: only $66 \%$ of able children of less advantaged families, but $85 \%$ from the more advantaged homes applied.

Unfortunately, Schoon's analysis does not extend into the period effects of the Great Recession on the youth's achievement orientation. 
Moving on to the USA, Mortimer, Zhang, Hussemann and $\mathrm{Wu}$ (this issue) analysed how children's achievement orientations are affected by economic hardship in their family in the period of the Great Recession, based on the longitudinal Youth Development Study (YDS). The YDS began in1988, when 14-15 year olds were contacted for the first time; they were followed through the transition to adulthood, and in 2008, their children too became part of the study. In this unique intergenerational study, 345 available parent-child pairs were reduced to a sample of pairs who completed surveys in 2009 and 2011, when the parents were 37 and 38 years old and their children 11 years and older.

The theoretical approach is a fine-grained social psychological model of status attainment, assuming that the sense of economic efficacy and educational and work-related plans are affected by changing economic circumstances. Following Elder's (1974) "Children of the Great Depression tradition, the authors ask how the economic hardship of the Great Recession" has impacted children's plans for the future.

The results are consistent with the UK study: achievement orientations of adolescents who are growing up in families with low education and unemployment experiences are more strongly affected by declining economic conditions, with boys more vulnerable than girls.

Mortimer et al focused on the children's sense of economic efficacy and educational aspirations and examined their association with household income in 2011. They also investigated the impacts of changing (declining) family economic resources between 2009 and 2011 on children's efficacy and aspirations. Are parent's unemployment history, their achievement orientations and educational attainment related to the way the children dealt with hardship?

Mortimer et al highlight, as a main result of their study, that the parents' efficacy when they were adolescents themselves is reflected in their children's economic efficacy. This inter-generational transmission of achievement orientation is also visible in the way changes in household income affected change in children's efficacy. Moreover, parents with at least a BA, stress education and guide their kids toward an academic pathway. They seem "to encourage their children in ways that spill over to their children's confidence in a manner that is protective, irrespective of the immediate economic situation of the family" (Mortimer et al, this issue, p.122).

Four potential moderators of the effects of family hardship were examined:

Parental work/employment career stability (52\% were not jobless from 1997 to 2007; 24\% were unemployed more than one month per year); the meaning of achievement in the family; children's gender (55\% female), and age (mean age 15.8).

The potential effects of experiencing hardship are discussed at the family and the individual level. Adaptive response to economic woes may trigger new skills and forward looking ideas, and the family may have found strategies of coming to terms with less money that absorb the shock effects on the children. If families have prior experience of cutting back, then they are better prepared to meet the consequences of the Great Recession. Such prior experience is indicated by the parent's long-term employment history since 1997 (as measured by a monthly record of employment status). In contrast, there is also the likelihood that already disadvantaged families, as a result of problematic work histories, become more vulnerable as current financial problems increase if their belief in their own efficacy diminishes. At the individual level, a core assumption is that when parental biographies are characterised by strong achievement orientations in adolescence then it is likely that these attitudes are transmitted to their offspring, instilling confidence in the future.

The measure of economic efficacy is rather limited, consisting of three items concerning the future: getting a job that pays well, being able to own one's own home, and having a job one enjoys doing; educational aspirations are just measured by one item: What is the highest level of education that you plan to obtain in the future? Unfortunately, there is no item asking how realistic these aspirations were.

When the parents were 15 to 16 years old their educational aspirations and efficacy were measured and, in adulthood, their educational attainment recorded. More than 20 years later, parents' economic efficacy, as adolescents, had a positive effect on their children's sense of efficacy (Table 2). This suggests a continuity of achievement orientation in the family and respective socialization practices. Children became more efficacious when parental confidence was high and 
incomes were rising (Figure 1). The more highly educated parents seem to succeed in protecting their children's sense of efficacy as financial problems increase (Figure 2).

Their parents' history of joblessness seems to have sensitized children to diminish their aspirations to the shifts in household income (Figure 3). Interestingly, the findings do not feature main or additive effects of recent economic hardships in the Great Recession on children's achievement orientations; instead, children's responses depended on parental achievement orientations, work histories, and attainments.

\section{Discussion}

These papers are embedded in a life course and social inequality framework: life chances are unequally distributed. It is hard for parents to break or divert this structured inter-generational relationship if they did not succeed in the education systems, live in a neighbourhood of multiple deprivations, work in non-standard jobs, and must come to terms with episodes of unemployment. Their efforts to instil educational and job aspirations and to promote their children's transitions that reach beyond the family's history of struggling with hardship, require a social policy that provides the resources for improving the family-school-labour market nexus.

As socialization research has shown over and over again, educational aspirations are class related and they are likely to change in response to transition outcomes. The subjective response to school and job experiences reflects young people's assessment of opportunities and results, which leads in most cases to increasing realism.

As the papers document, the Great Recession did not seem to have had a strong impact on youth transitions, however, social inequalities loom larger than at the end of the last century. The consequences of the Great Recession for youth transitions have been filtered by the respective social and political fabrics of the UK, USA, and Germany. Again, though this is a truism, it should forewarn us against premature causal assumptions about the impact of globalization and financial and economic crises, since policy interventions differed by the paths of social market economies and (neo) liberal market societies.

Twenty-five years ago, the effects of the declining economic status of young people in the
USA on their pathways to education and work were analyzed in the report the "Forgotten Half" (William T. Grant Foundation, 1988). Ten years later, the forgotten half was revisited (Halperin, 1998) with an outlook for 2008. The results are discouraging: though more are starting post-secondary education, youth who do not succeed to start, or do not finish college, face living circumstances worse than ten years ago, and young men are more often affected than women. Youth who come from lower social backgrounds often lack the awareness and the means necessary for entering college. These early career decisions restrict employment opportunities. The effect of pursuing a higher education pathway on later earnings was greatest for students who were the least likely to go to university, as Brand and Xie (2010) showed.

For disadvantaged youth, access to the means of competence production (from kindergarten to lifelong learning), labour market opportunities and community life, depends more and more on formal and informal policies of inclusion. The family's vulnerability in times of economic uncertainty increases with the parent's lack of post-secondary education and unemployment episodes; these cumulative disadvantages exacerbate the negative effects of the Great Recession. Therefore, social policy must strengthen parents' agency by providing educational resources and job training and creating self-confidence in children by tutoring and mentoring practices.

When we ask the crucial question of how social inequality is reproduced in the transition to adulthood, several layers of contributing factors and processes must be taken into account: Family background, gender and living circumstances, but especially institutions, pathways and opportunity contexts, matter. For example, in labour markets with a low unemployment rate, the transmission of joblessness from father to son did not occur (Macmillan 2010).

Another dimension of social inequality is gender. As the papers suggest, young men are more affected by their families' economic hardship and especially their fathers' unemployment than young women. Where the male norms of becoming prepared for the breadwinner status still prevail, it is likely that boys take a loss of family resources more seriously than girls, who will not reduce their education and job aspirations. One explanation is that young women leave home earlier and that 
young men may identify with the role of the male family provider, which is threatened by their fathers' (persistent) unemployment.

A more general comment concerns the challenge of explicating macro-micro links.

The papers in this Special Section apply advanced methods of longitudinal data analysis, but reflect the lack of theory, which is characteristic of life course and youth research. Research would gain validity with a framework that could explicate the linking mechanisms (Elder. 1995) of social structure and personality. A distinction between empirical models and conceptual models of causality should be made. The former test statistical relationships, the latter enable asking questions and interpreting results in a theoretical framework

In my view an important candidate for theoretical development is the concept of agency, which can help to delineate a crucial social and psychological mechanism that mediates the effects of individuals' contextual history on transition outcomes. The notion of agency has become a catch-all term, characterizing the person's engagement in constructing their biography. It refers to the capacity to mobilize resources for selfmonitoring of decisions and their outcomes. This competence depends on the individual's contextual history (characterising biographical transitions and events), which is related to, but not determined by, social origin.

Depending on theoretical perspectives, agency is associated with dispositions, motives, abilities, creativity, habitus, imagination, competence, and the knowledge of cultural scripts, all of which are mobilized at transitions and tuning points (see Sewell, 1992).

The notion of agency has been used more like a treasure chest for importing the actor's subjectivity into life course analysis. It is time for putting agency into a tool-box for transition research by delineating its characteristics. What are the components of agency? In order to answer this crucial question, a heuristic micro-sociological approach integrating the developmental and social psychology of personality and identity construction is sketched.

I suggest drawing on the concept of personality factors in the context of quantitative life course study and on the concept of reflexivity for qualitative biographical studies.

Personality is well represented by the "big five", a descriptive cluster of interdependent factors:
Open mind (imagination), Conscientiousness, Extraversion (socially engaged) Agreeableness (empathy), and Neuroticism, abbreviated OCEAN (see Fleeson, 2001; Roberts, Wood \& Smith, 2005).

The role of selected personality dispositions like self-regulation, control beliefs, and self-esteem seem to vary by opportunity structure and cultural norms of individual responsibility for unemployment and social mobility. Diewald, Solga, Goedecke (2006) have illustrated these complex relationships during the restructuring of the life course after the fall of the Berlin Wall. Dispositions seem to be affected by dramatic life course events turning points - rather than the other way around.

Especially for youth research, agency should be explicated by reference to the actor's reflexivity and capacity to mobilize a set of resources for the purpose of navigating transitions (see Sewell, 1992; Archer, 2012). Reflexivity is an important component of agency, presuming interrelationships among identities, life scripts, opportunities, and institutions. Biographical reflexivity implies contextual sensitivity and a time-horizon: thinking back for getting ahead. Aspirations are reflections about the future: "Agency is exerted differentially depending on the actor's salient time horizon" (Hitlin \& Elder, 2007, 171). In a temporal perspective, agency refers to three levels: Getting things done (present), remembering past decisions and outcomes (subjective causality: memory), and life projections (enacting a script).

To examine the contribution of the reflexive component of agency to decision-making about pathways and the biographical shaping of transitions, qualitative longitudinal case studies are the adequate procedure.

Another theoretical problem is to explain how "an endogenous developmental path" is unfolding when, for example, the risk zone of poverty diminishes with increasing age (Groh-Samberg (this issue) p. 163). The developmental path is based on agency, which means coming to terms with changing contexts and creating subjective continuity, an achievement that requires a self-reflexive mobilization of resources. For example, as the papers by Schoon and Mortimer et al suggest, parental unemployment hardship triggers young people's active responses that may reduce longterm life course consequences only when parents are well educated and promote high aspirations. 
As Dannefer and Uhlenberg (1999) pointed out, young adults have to translate their formative experiences in childhood and adolescence into action contexts of the contemporary social structure. The discrepancy between short-term transition outcomes and long-term returns, results from the contingency of life courses. The social structuration of life courses implies the individual shaping of one's biography by taking or evading risks (O'Rand, 2003), constructing and rewriting life scripts, investing time and resources for achieving, maintaining or improving one's standard of living.

What Archer (2012) called "contextual incongruity" poses the question, to what extent can values, aspirations, and orientations really be transmitted from parents to their offspring? Youth have to shape their transitions from education to employment in economic and socio-cultural contexts that differ from their childhoods and from their parents' experiences. Over the last decades, "socialization has been decreasingly able to 'prepare' for occupational and life style opportunities" (Archer, 2012, 82). For example, fathers did not need the BA and had stable employment, and mothers were part-timers, whereas both their sons and daughters study for the $\mathrm{BA}$ and expect flexible employment and unstable careers.

Micro-social models must be linked with concepts specifying patterns of development in context. Moreover, there is no direct link between macro-level structures and micro-level processes: the meso-level of institutions intervenes. This complexity must be considered in cross-national comparisons of youth transitions. A complete analysis of causes of disadvantage in adolescence and young adulthood would require a conceptual multi-level framework that captures the entire macro-meso-micro link: time-dependent decisionmaking and action in changing social and institutional contexts and varying economic circumstances.

Furthermore, for comparative analyses a sound theoretical model is required that includes institutional arrangements and the changes in such arrangements resulting from the impact of globalization - a model more specific than the popular concept of welfare regimes (see Mayer, 2009). The standard multi-country comparisons like the Programme for International Student Assessment (PISA) are lacking the specifications that are essential for deriving sound conclusions about the life course outcomes of various "transition regimes". The transition to young adulthood is contextualized by institutionalized pathways in education and employment, which provide resources and guidance. However, without parental support and employment prospects young people are at a loss in predicting their returns on investment in education.

To better understand and explain how the relationships between family, school, neighbourhood, labour markets, and institutions unfold, and how they promote or restrict the timing, duration and outcome of transitions to adulthood, more qualitative longitudinal case studies to supplement large scale life course study would be desirable. Such an approach would improve our capacity to explain why youth living in different social contexts decide to embark on academic, vocational or precarious pathways and how they are coming to terms with the intended and unintended biographical consequences.

\section{References}

Archer, M. S. (2012). The reflexive imperative in late modernity. Cambridge: Cambridge University Press. http://dx.doi.org/10.1017/CBO9781139108058

Blossfeld. H.-P., Klijzing, E., Mills, M., \&Kurz, K.(eds.). (2005). Globalization, uncertainty, and youth in society. London: Routledge.

Brand, J.E., \& Xie, J. (2010). Who benefits most from college? Evidence for negative selection in heterogeneous economic returns to higher education. American Sociological Review 75, 273-302. http://dx.doi.org/10.1177/0003122410363567

Buchmann, M. C., \& Kriesi, I. (2011). Transition to adulthood in Europe. Annual Review of Sociology 37, 481503. http://dx.doi.org/10.1146/annurev-soc-081309-150212

Crosnoe, R. \& Jonson, M.K. (2011). Research on adolescence in the 21st century; Annual Review of Sociology 37, 439-460. http://dx.doi.org/10.1146/annurev-soc-081309-150008 
Dannefer, D. \& Uhlenberg, P. (1999) Paths of the life course: A typology. In V.L. Bengtson, \& K.W. Schaie, (Eds.), Handbook of Theories of Aging (pp.306-326). New York: Springer.

Diewald, M., Solga, H., \& Goedecke, A. (2006) Old assets, new liabilities? How did personal characteristics contribute to labour market success or failure after 1989? In: Diewald, M, Goedecke, A. \& Mayer, K.U. (Eds.), After the fall of the wall: East German life courses in transition (pp. 65-88). Stanford: Stanford University Press. http://dx.doi.org/10.11126/stanford/9780804752084.003.0004

Elder, G.H. Jr. (1995). The life course paradigm: Social change and individual development. In Moen, P., Elder, G.H., \& Lüscher, K. (Eds.), Examining lives in context: Perspectives on the ecology of human development (pp. 101-136). Washington, DC: American Psychological Association. http://dx.doi.org/10.1037/10176-003

Fleeson, W. (2001). Towards a structure-and- process-integrated view of personality; traits as density distribution of states. Journal of Personal and Social Psychology 80, 1011-1027. http://dx.doi.org/10.1037/0022-3514.80.6.1011

Groh-Samberg, O., \& Voges, W. 2014. Precursors and consequences of youth poverty in Germany. Longitudinal and Life Course Studies 5, 151-172. http://dx.doi.org/10.14301/llcs.v5i2.281

Halperin, S. (ed.) (1998). The Forgotten Half Revisited. American Youth and Young Families, 1988-2008. Washington, DC: American Youth Policy Forum.

Heinz, W.R. (2009). Structure and agency in transition research. Journal of Education and Work 22, 391-404. http://dx.doi.org/10.1080/13639080903454027

Hitlin, S., \& Elder, G.H. Jr. (2007). Time, self, and the curiously abstract concept of agency. Sociological Theory 25, 170-191. http://dx.doi.org/10.1111/i.1467-9558.2007.00303.x

Lareau, A. (2004). Unequal childhoods: Class, race, and family life. Berkeley: University of California Press.

MacMillan, L. (2010). The intergenerational transmission of worklessness in the UK. Bristol: CMPU.

Mayer, K.U. (2009). New directions in life course research. Annual Review of Sociology 35, 413-433. http://dx.doi.org/10.1146/annurev.soc.34.040507.134619

Micklewright, J., \& Anders, J. (2013). Teenagers' changing expectations of applying to university; working paper. London: University of London, Institute of Education.

Mortimer, J.T. (2003). Working and growing up in America. Cambridge: Harvard University Press.

Mortimer, J.T., Zhang, F.L., Hussemann, J., \& Wu, C-Y. 2014. Parental economic hardship and children's achievement orientations. Longitudinal and Life Course Studies 5, 105-128. http://dx.doi.org/10.14301/llcs.v5i2.271

O'Rand, A.M. (2003). The future of the life course: Late modernity and life course risks. In Mortimer, J.T. \& Shanahan, M.J. (Eds.), Handbook of the life course (pp. 693-702). New York: Kluwer Academic. http://dx.doi.org/10.1007/978-0-306-48247-2 33

Roberts, B., Wood, D., \& Smith, J.L. (2005). Evaluating five factor theory and social investment perspectives on personality trait development. Journal of Research in Personality 39, 166-184. http://dx.doi.org/10.1016/i.jrp.2004.08.002

Schoon, I. 2014. Parental worklessness and the experience of NEET among their offspring. Longitudinal and Life Course Studies 5, 129-150. http://dx.doi.org/10.14301/llcs.v5i2.279

Sewell, W. A. (1992). A theory of structure: Duality, agency, and transformation; American Journal of Sociology 98, 1-29. http://dx.doi.org/10.1086/229967

Shildrick, T., MacDonald, R., Furlong, A., Roden, J. \& Crow, R. (2012) Are 'cultures of worklessness' passed down the generations? York: Joseph Rowntree Foundation.

Staff, J., Johnson, M.K., Patrick, M., \& Schulenberg, J. 2014. When teenage work disappears. Longitudinal and Life Course Studies 5, 173-188. http://dx.doi.org/10.14301/llcs.v5i2.275

Standing, G. (2011). The precariat. The new dangerous class. London: Bloomsbury. http://dx.doi.org/10.5040/9781849664554

Valentine, C.A. (1968). Culture and Poverty. Chicago: University of Chicago Press.

William T. Grant Foundation (1988) The forgotten half. Washington, DC: W.T.Grant Foundation.

Wissenschaftszentrum für Sozialforschung Berlin (WZB). (2013). Datenreport. Ein Sozialbericht für die BRD. Berlin: WZB. 